\title{
10
}

\section{THE LAW OF STATISTICAL REGULARITY AND ITS SOCIO-ECONOMIC SIGNIFICANCE}

\author{
S. I. Idele
}

\begin{abstract}
This paper considers the law of statistical regularity which has transposed statistics from being merely a quantitative discipline to an inferential one. In particular, the physico-mathernatical basis of statistical regularity has been analyzed as the bedrock upon which the socio-economic superstructure is erected. This has made the central concept in statistics to enjoy a wide range of empirical applications in this paper, including the determination of the market equilibrium prices of OPEC oil in the long-run, the stabilization process of male-female ratios of births in the semi-stable population of Nigeria and the institutionalization of stable national insurance policies for the country, hi fact, it is this extended - and indeed innovative - use of the law of statistical regularity that gives this study its utilitarian and heuristic significance for the articulation of viable, stable and crisisfree national development policies.
\end{abstract}

\section{INTRODUCTION}

The quantitative attributes of statistics, as distinct from those of its parent mathematics, are stable, well-ordered and free from major stochastic disturbances - the qualities 
which have made statistical discipline the unique and erudite branch of knowledge that it is today. Specifically, the stable attributes of quantitative statistics have, as it were, historically coalesced into both the "Law of Statistical Regularity" and the "Law of Inertia of Large Numbers". These important laws, by virtue of their symmetrical nature, are now being applied interchangeably, with the former representing the omnibus law while the latter constitutes its derived theorem or group of theorems (Kuznetsov 1968; Rose 1972).

However, the historical link is still there and, therefore, it is important to bear in mind all the time that the law of large numbers is, nonetheless, a mathematical and probabilistic category adapted and used in statistical theory as an important foundation of the subject. It has in fact transposed statistics from being merely a quantitative discipline to an inferential one. In particular, it is upon the law that the sampling theory is based, thanks to the commendable works of the great pioneers such as Jakob Bernoulli-( 16541705). S. D. Poisson (1781-1840) and, perhaps, the greatest of them all, the Russian Mathematics prodigy, P.L. Cheby-Chev (1821-1894), whose "theorem is the most general law of large numbers and Bernoulli's the simplest" (Gmurman 1968). Among other things. Chebychev's theorem explains why we may judge the quantity of a large amount of homogeneous materials from a small sample.

The major objectives of this paper can be summarized as follows. Firstly, we intend to give a more comprehensive definition of the law of statistical regularity and compare it with the law of large numbers. This is because of the fact that the latter law is an important corollary of the former and. as such, it is difficult to fully understand what the basic theorem stands for without studying its corollary side by side with it. Secondly, we shall briefly analyze the physical basis of statistical regularity in the light of some empirical illustrations. This procedure is perhaps useful because statistical regularity itself, being a static and dynamic concept, is built essentially on physical sciences foundations. Finally, we propose to demonstrate how the basic tenets of statistical regularity can be usefully extended from their physical science base to the social sciences with some first-hand examples.

\section{CONCEPTS, DEFINITIONS AND THE PHYSICAL BASIS OF THE LAWS}

\section{The Law of Statistical Regularity}

One of the best available definitions of the law of statistical regularity is that given by W. I. King (1989) as follows: 


\section{Annals of The Social Science Council of Nigeria, No. 7, January-December, 1995}

The law of statistical regularity lays down that moderately large items chosen at random from a large group are almost sure on the average to possess the characteristics of the large group.

The concept of statistical regularity, both as a static and dynamic category, clearly has many attributes amongst which three are of special relevance to us in this study. Firstly, and as we have already remarked, the concept is an "omnibus" law rather than a "derived" theorem, per se. Thus, any mass-scale phenomena which exhibit some discernible form of central tendency naturally fall under this law. Consequently, being global in outlook, the law of statistical regularity manifests itself through one or more of its derived theorems and their corollaries. These include the Classical Limit Theorem, the Central Limit Theorem, the Theory of Stochastic Processes, the Queueing Theory, the Markov Chain - "Regular" and "Absorbed" - and, of special relevance to the rest of this paper, the Chebychev's Theorem of the Law of Large Numbers, "Strong" or "Weak" (Mizrabi 1972).

Secondly, since the law of statistical regularity is itself a veritable "derivative" of the random sampling theory, it obviously generates probability distributions. Indeed, the content of probability theory - as the bedrock of statistical theory -corresponds to the foregoing concept of statistical regularity, for probability theory may be defined as the science of distributions and their general properties that necessarily give rise to such distributions which, according to Sachkov (1968), "may be symmetrical -er asymmetrical".

Finally, the law of statistical regularity originated in the physical sciences over a century ago, thanks mostly to the epic works of the Scottish physicist and mathematician, James Clerk Maxwell (1831-1879) who, for the first time, discovered the existence of statistical regularities in the physical movements of the molecules of gases in the famous Maxwell Kinetic Theory of Gases. About the same time, the renowned nineteenth-century English biologist, Sir Francis Galton (1822-1911), in his book Hereditary Genius, written in 1869, also discovered statistical regularity hi the part played in the selection of human species, sex, reproduction, Intelligent quotient (IQ) and the long-run tendency for human heights to revert back to the universal mean which, according to the author himself, meant "stepping back towards the average" or a regression to mediocrity" (Yule, G. U. et al 1968).

Today, more than ever before, the application of statistical regularity has extended from its physical sciences foundation to the social sciences such as the Actuarial Sciences, Accountancy, Demography and Cybernetics. A more detailed analysis of such social applications constitutes the main focus of this paper, and this will be explored further presently. 


\section{The Law of Inertia of Large Numbers}

As stated earlier, the law of statistical regularity is the universal law while the law of large numbers constitutes its important corollary (or "lema") which has itself developed into the full-blown Theorem of the Law of Large Numbers over the years. The development of this great theorem - perhaps the only theorem in statistics to rival the well-known Central Limit Theorem - has had a very fascinating history involving the works of a number of classical writers. Amongst the contributions of such pioneers, Chebychev's Theorem of the Law of Large Numbers is perhaps the most authoritative to date.

Now, the definition of the law of large numbers is fairly simple, and this would be viewed from the formal, technical or applied perspectives. According to the formal definition given by Professor S. P. Gupta (1985):

The law of large numbers states that, other things being equal, the larger the size of the sample, the more accurate the results are likely to be. This is because large numbers are more stable when compared to small ones. The difference in the aggregate result is likely to be insignificant, when the number in the sample is large because when large numbers are considered the variations in the component parts tend to cancel out each other.

Technically put, the law of large numbers states that the deviations of the sample mean (x) from their population mean $(\mathrm{u})$ tend to be very pronounced for small samples; however, as the sample size increases indefinitely (i.e. as n oo), these deviations tend to die off in a wave-like fashion until the same sample mean eventually converges with the population mean.

In practical terms, the basic principle of the law of large numbers states that, at first blush, it appears difficult to forecast the general principles governing the behaviour of a multitude of random processes. In the end, however, as the random variables involved in these random processes increase indefinitely in number, they tend to lose their randomness, become pretty steady and their general behaviour becomes fairly predictable.

At this stage, it is perhaps worthwhile to briefly review (without formal proofs) the individual contributions of some of the leading pioneers in the theoretical development of the law of large numbers.

To start with, the theorem proved by Jacob Bernoulli (1654-1705) in his epic work Arts Conjectandi (published posthumously in 1713) was dedicated to answering the vital question as to why the relative frequency - that is, the ratio of the number 
of trials in which the event occurs to the total number of experiments performed - tends to stability the larger the number of such trials in an experiment becomes (R. Von. Mises, 1939).

Empirical illustrations of Bernoulli's theorem abound in real life, amongst which we may cite the interesting example of the coin-tossing experiments performed by Gfeorge Buffon, the eighteenth-century French naturalist, and Karl Pearson, generally regarded as perhaps the greatest English Statistician of all times. The results are displayed in Table 1.

Table 1

Coin-Tossing Experiments

\begin{tabular}{|l|l|l|l|}
\hline By Whom Performed & No. of Throws & No. of Heads & $\begin{array}{l}\text { Relative } \\
\text { Frequency }\end{array}$ \\
\hline $\begin{array}{l}\text { George Buffon Karl } \\
\text { Pearson } \\
\text { Karl Pearson }\end{array}$ & $\begin{array}{l}404012000 \\
24000\end{array}$ & $\begin{array}{l}20486019 \\
12012\end{array}$ & $\begin{array}{l}0.5080 \\
0.5005\end{array}$ \\
\hline
\end{tabular}

Source: $\quad$ V.E. Gmurman (1968): Fundamentals of Probability Theory and Mathematical Statistics. London: life Books Limited, p. 8.

From Table 1, it is seen that the relative frequencies do not deviate appreciably from 0.5 , which represents the probability of an unbiased coins falling "heads". At the same time, it is even more striking to note that, as the number of trials in a single experiment progressively increases, the lesser the deviation tends to be from 0.5 .

The next stage in the development of the law of large numbers was when S. D. Poisson (1781-1840) successfully demonstrated that Bernoulli's theorem was also valid with variable probabilities. The only proviso in this respect was that the successive trials in the experiment be performed independently of the results of the preceding trials, analogous to the role played by "transitional probabilities" in the Markov Chain (Hoel 1974).

As an illustration, the Poissonian model is identical with picking balls at random not from one and the same urn, but from several urns in each of which the composition of the balls is entirely different. Clearly, the probability of picking a ball of a given colour will ultimately depend upon the particular urn from which a particular ball is picked. So Poisson postulated that, in the circumstance, instead of one (constant) probability, we should compute the "mean probability" from a finite array of different probabilities which hi fact do exist in real life. 
Finally, P. L. Chebychev (1821-1894) further updated the earlier works of his two masters, Bernoulli and Poisson, who had much earlier built their theorems essentially around a single relative frequency. Chebychev, however, hypothesized that, in practice, there normally exist not just one but a multitude of random phenomena which exhibit multiple functional relationships. He, therefore, built his own theorem on the arithmetic means in the form of mathematical expectations of all the random variables concerned rather than their individual relative frequencies. The great Russian mathematician thus successfully contrived an "omnibus theorem" which, in essence, is nothing other than the well-known Chebychev's theorem of the law of large numbers - "Weak" or "Strong" - as we know it today.

Illustrative examples of the operation of the law of large numbers abound in both physical and social sciences, amongst which we now cite one example from the former disciplines, leaving the empirical illustrations of the latter for a more detailed analysis in the next section.

Now, in accordance with the relevant law in molecular physics, a gas is made up of an enormous quantity of random particles which are in chaotic motion. Considering only one isolated molecule, we cannot for sure predict its velocity or where it will be located in the next moment. However, we can. all things being equal, compute the portion of all the molecules put together that will likely be moving with a given velocity or the portion of them that will be located in a given volume of space. That is precisely what the physicist wishes to know, since the basic characteristics of gas - pressure, temperature, viscosity, and so forth - are determined not by the bizarre and fortuitous behaviour of only one and isolated molecule but by the collective propagation of all of them in space. Thus, the pressure gas is equal to the overall action of molecules impinging on a plate of unit area in unit time. True, the number of impacts and the speeds of the impinging molecules vary considerably according to chance; however, by virtue of the law of large numbers (in Chebychev's form) the pressure should be very nearly constant. This "equalizing" effect of the law of large numbers in physical phenomena is exhibited with exceptional precision.

\section{SOME SOCIAL AND ECONOMIC APPLICATIONS}

Having briefly reviewed the physical basis of the law of statistical regularity -together with its twin concept of the law of large numbers - we now proceed to some detailed analysis of the major social and economic applications of the law. 


\section{Stability of Demographic Events: The Nigerian Fertility Scenario}

So far, we have studied statistical regularity in the form of stability in the relative frequencies of the mass-scale phenomena concerned. In practice, this type of stability of frequencies has long been observed in the demographic history of some countries of the world, particularly those in South-Eastern Asia. For instance, in China, Japan and India - the "Great Orientals" - Chavalier (1965) has posited that, during the 17th and 18th centuries in that part of the world, apart from the stability in the births of boys and girls, stable regularities were also recorded in other demographic variables as well. These included the total number of deaths in definite age brackets for specific groups of the population, the spatial distribution of the population, the national migration patterns, and so on.

More specifically, P. S. M. Laplace (1749-1827), the renowned French mathematician, physicist and astronomer — the "Newton of France" — had in the meantime successfully carried out some indepth studies of similar fertility data in London, Brussels, Berlin and other European cities. The results from these places yielded virtually the same male birth ratios which fluctuated steadily around the overall mean figure of 22:43 (or0.5116)(Gnedenko, 1969). Unfortunately, however, Laplace's home tome, Paris, in respect of the forty years covered by his studies between 1745-1784, produced a slightly different male ratio of $2 * 49$ (or 0.5102 ).

Intrigued by this discrepancy, Laplace started to dig into the national archives for a rational solution. Eventually, it was revealed that the total number of births in Paris centre at that time included all foundlings (i.e. deserted or abandoned children of unknown parentage) including those from the suburbs where the local population were in the habit of abandoning infants of one sex, mostly females. This social aberration was so rampant that it appreciably distorted the true picture of births in paris at that time. When Laplace consequently eliminated the suburban foundlings from the total number of urban births, it was found out that for Paris as well the ratio of male births was likewise stable and that this was hi fact very close to the universal mean of 22:43 (or 0.5116 ).

In Nigeria, since it is only the provisional 1991 Census results that have been published to date (vide: The Guardian of March 20,1992), we have made a recourse to the birth data provided in the 1950 Lagos Census, the 1963 Nigerian and Mid-Western Nigeria Population Censuses and the UN (1994) "Middle Variant" Estimates for the whole century in respect of the years 1990,1995 and 2000, respectively.

Table 2 presents the graphic details of the results achieved in respect of the birth history and fertility prospects of the country for selected years between 1950-2000. In particular, column 5 of the table is of special significance for this study as it exhibits a remarkable stability in the ratios of the male births to the total births 
The Law of Statistical Regularity and Its Socio-Economic Significance 169

which fluctuate steadily around the overall national mean male birth ratio of 0.4932 . This result is quite encouraging — and can perhaps be provisionally accommodated - even though we cannot as such rule out the presence of some "compensating variations" in the error terms emanating from the rather unsophisticated census data feed-back systems available in Nigeria at that time.

Table 2

Distribution of Male Births Ratios in Nigeria, 1950-2000

\begin{tabular}{|c|c|c|c|c|}
\hline $\begin{array}{l}\text { Geographical } \\
\text { Area }\end{array}$ & $\begin{array}{l}\text { Year of } \\
\text { Observation }\end{array}$ & \begin{tabular}{|l} 
Births \\
Male
\end{tabular} & Female & $\begin{array}{l}\text { Male } \\
\text { Ratio }\end{array}$ \\
\hline$(1)$ & (2) & (3) & (4) & (5) \\
\hline Lagos Total & 1950 Census & 16241 & 16694 & 0.4931 \\
\hline Edo Total & 1963 Census & 15004 & 15966 & 0.4845 \\
\hline Edo Urban & 1963 Census & 2118 & 2083 & 0.5042 \\
\hline Edo Rural & 1963 Census & 12886 & 13879 & 0.4814 \\
\hline Nigeria Total & 1963 Census & 760072 & 786009 & 0.4916 \\
\hline Nigeria Urban & 1963 Census & 103746 & 103958 & 0.4995 \\
\hline Nigeria Rural & 1963 Census & 656326 & 682051 & 0.4904 \\
\hline Nigeria Total & 1990 Estimates & 47597 & 48556 & 0.4950 \\
\hline Nigeria Total & 1995 Estimates & 55373 & 56348 & 0.4956 \\
\hline Nigeria Total & 2000 Estimates & 63900 & 64886 & 0.4962 \\
\hline $\begin{array}{l}\text { vfational } \\
\text { Iverage }\end{array}$ & & 173326 & 179043 & 0.4932 \\
\hline
\end{tabular}

Sources. (a) 1950 Population Census of Lagos

(b) 1963 Mid-Western Nigeria Population Census

(c) 1963 Nigeria Population Census

(d) 1994 United Nations "Medium Variant" Population Estimates 


\section{Stabilization Processes in Market Equilibrium: The OPEC Bench Price}

The problem of the exact location of the market equilibrium price is perhaps the most topical issue of modern microeconomic theory. In this respect, we can identify some three phases of the historical development of price determination with each phase being linked with the classical and neo-classical doctrines of Alfred Marshall, William Baumol and Oskar Lange, respectively.

The mathematical formulation of the three elementary laws of demand and supply - and hence the prototype version of the market equilibrium price - was originally developed by Afred Marshall (1892), Leontief (1929), Schultz (1938), and others. According to them, "the demand and supply curves represent the two intersecting lines of best fit inserted each by the method of least squares through the mean of the array of the two 'families' of empirically distributed demand and supply scatter diagram" (Leontief 1929). It is the point of intersection of the demand and supply curves that constitutes the market equilibrium price. An intuitive reflection will show that this type of equilibrium price has the tendency to stabilize so long as the market for the commodities expands in size in conformity with the law of large numbers, the Chebychev type. Unfortunately, however, such an equilibrium model merely reflects a short-term rather than long-term market situation, and herein lies the major deficiency of the rather simplistic Marshallian model.

The next stage in the development of the price theory was reached when William Baumol (1965) and Oscar Lange (1959), working independently, successfully "finetuned" and extended the short-run equilibrium model of Alfred Marshall and his scholars by introducing the "long-term factor" and "functional stability" into it.

Professor Lange, generally regarded as the father of modern econometrics, was of the view that the longer the time frame, the more likely it is that some endogenous disturbances would intervene to shift the original demand and supply curves bodily outward or inward from their original positions, hi his model, a network of several demand and supply curves emerged. The tendency for these curves was to intersect at fairly regular intervals, arranged in a parallel formation and reflecting identical demand and supply elasticities. This long-term stabilization scenario is depicted in Fig. 1, where the several points of intersection of the corresponding demand and supply curves from $E_{n}$ to $\mathrm{E}_{44}$ constitute the multiple long-term equilibrium prices.

However, in spite of the great merits of the foregoing model of the long-term dynamic equilibrium prices enunciated by Lange, it is difficult to decipher the most optimal market equilibrium price amongst the rich plethora of intersections of demand and supply curves in the prototype model. In fact, the scholar himself, wittingly or unwittingly, personally admitted this glaring deficiency in his model for, according 
Fig.l

\section{Oscar Lange's Model of Long-run Equilibrium Prices}

\section{PRICE}

\section{QUANTITY}

to him, "the curves connecting the several points of equilibrium in the various years do not give any specific economic picture" (Lange 1959). Lange also ventured extensively into the study of the "cobweb model", but it is the contemporary work of William J. Baumol that is perhaps still the most authoritative to date on the subject.

Almost simultaneously, Baumol worked on the infusion of some "definiteness" and "stability over time" into the original Marshallian short-term dynamic equilibrium price model. This he did by an identical approach to Lange's model. However, the novelty of his approach is his insistence on the fact that any well-meaning equilibrium situation must possess certain inbuilt long-run tendency towards some definite, stable and predictable limit, i.e., either to "converge" or "diverge", as the case may be in consonance with the demand and supply elasticities of the commodities concerned. Baumol immodestly termed his contribution the "more realistic" model of dynamic equilibrium and ingeniously embodied it in his famous "cobweb theorem" with the application of the single-equation dynamic model (Blalock 1969).

We now proceed to a brief examination of the practical relevance of the cobweb model in the stabilization process of the bench-mark prices of the crude oil marketed by the Organization of Petroleum Exporting Countries (OPEC) since 1970. Here, two highly contrasting models could be articulated. 


\section{Annals of The Social Science Council of Nigeria, No. 7, January-December, 1995}

The first model indicates when oil producers become hysterical and resort to a unilateral and pre-emptive increases in production perhaps as result of an anticipated rise in demand. The volatile nature of oil this makes the producers to become unduly overoptimistic and plan much higher output than would have been normally justified by the expected - but yet unrealized - rise in prices. As a result of such a precipitate course of action, taken by the producers almost to the utter disregard for the prevailing market situations, the market becomes over-stocked with oil. This simplistic model, according to Blalock (1969), suggests that the suppliers are each time over-correcting by an increasing amount, so that they continually "over-shoot the mark", creating greater and greater peaks and troughs. Then mass hysteria quickly sets in again and, by a reverse process, production is inevitably curtailed, this time far below the actual market demand. These fluctuating processes of over- and under-production for the market alternate, interestingly, in a spiralling, cobweb fashion, leading to so-called "explosive oscillation" without ever achieving any market equilibrium.

The foregoing oil destabilization scenario was experienced by OPEC in the early seventies, and two main reasons - one remote and the other immediate - are usually given as being responsible. On the one hand, "there has been an international inflationary rise in prices since the mid-sixties which presumably culminated to the demise of the fixed exchange rate system in 1971" (Osayimwese and Onimode 1980). On the other hand, the oil crisis was triggered off by the Yom Kipper War of 1973 and, in particular, the Arab-Israeli War of the same year together with the consequent Arab embargo on the Western countries. This situation made the US - the then OPEC's single largest market - to make a pre-emptive recourse of her "Strategic Oil Reserve" and some Western countries to step up their research into alternative sources of power, with France leading the way in solar energy. Consequently, as evident from Table 3, 1973 stands out on record as the year which recorded the lowest bench-mark prices for OPEC oil for the last twenty-three years, inflation or no inflation.

The other model, which is perhaps the more realistic one, is summarized in Fig. 2 drawn on the basis of the data contained in Table 3. The figure depicts the stabilization process which has crystallized in the OPEC crude oil market since the early seventies. The scheme presented here is that the supply function of the organization's crude was steeper (and therefore less elastic) than its demand function at the time. This implied that the supply for oil was in a short-run "lagged" response to effective market demand for the commodity, the state of affairs which considerably bolstered up the short-run prices of the commodity. Thus, in the light of the existing high oil prices, its long-run demand curve, $D_{0}$, shifted negatively to $\mathrm{D}$, implying some marginal reduction in effective price of the commodity. This situation consequently led to a new quest for a more realistic equilibrium price moving successively through the equilibrium points, $\mathrm{P}_{0}, \mathrm{P}_{1}$, 
$\mathrm{P}, \ldots \mathrm{P}_{\mathrm{t}}$, i.e., tracing the "time-path" from the old bench price for oil to the new one. Incidentally, the theoretical and practical significance of the cobweb diagram lies in the fact that the more elastic the supply curve for oil is the lesser the number of "amplitudes of equilibrium", and vice versa. But the OPEC oil supply then was less elastic in the

Table 3

Oil Price Development of Selected OPEC Crude $(\$ / b)$

\begin{tabular}{|l|l|l|l|}
\hline Year & Bonny Light & Arabian Light & Dubai \\
\hline 1970 & n.a & 1.80 & n.a \\
1973 & 5.10 & 3.62 & 3.75 \\
1974 & 14.19 & 11.58 & 11.59 \\
1975 & 12.17 & 12.38 & 11.48 \\
1980 & 35.64 & 31.19 & 29.93 \\
1981 & 36.75 & 34.00 & 35.59 \\
1982 & 35.50 & 29.00 & 33.86 \\
1983 & 30.00 & 29.00 & 28.86 \\
1984 & 28.00 & 28.00 & 28.86 \\
1985 & 28.65 & 13.64 & 26.95 \\
1986 & 14.94 & 17.23 & n.a \\
1987 & 18.50 & 13.40 & 16.92 \\
1988 & 15.11 & 16.21 & 13.18 \\
1989 & 18.50 & 17.82 & 15.64 \\
1990 & 24.16 & 17.89 & 20.38 \\
1991 & 20.59 & n.a & 16.62 \\
1992 & 19.93 & n.a not available & 17.16 \\
1993 & 14.45 & & 11.95 \\
\hline Note & n & &
\end{tabular}

Source: (a) OPEC Annual Statistical Bulletin. 1990 and 1991 Editions

(b) Vanguard, 23/3/94. pg. 17

short-run than the demand for it. as earlier stated. This was what naturally traces our the "damped oscillatory" time path phenomenon of the model, leading to the long-run market equilibrium price of 14.49 US Dollars per barrel in 1993.

This price trend was maintained with some marginal increases all through 1994-95 up to 1996 when the OPEC oil price suddenly appreciated to 24.10 US Dollars per barrel.

The majority of OPEC member countries naturally revelled at this desirable development which mainly due to the American involvement in the Kudish 
disturbances in Northern Iraq. This development has significantly undermined nor only the Iraqi OPEC export quota in oil but the organization's overall export stock of the commodity on a global basis, thus triggering off the current price hike.

Fig. 2

Stabilization Process for OPEC Oil Bench mark Prices 1980-93

$$
\mathrm{P}_{1993}-\$ 14 \mathrm{P}_{1980}=\$ 29
$$

n.a $=$ Not Available

n.a $=$ Not Available

Source Adapted from Allen, R. G.D. (1976): Mathematical Economics. London: Macmillan, p.3, and MEHTA, B.C., et al. (1986) Mathematical Economics. New Delhi: Sultan Chand \& Sons, p.447.

\section{The Imperatives of Forging Stable National Insurance Polices: Some Recent Evidence from the Nigerian Macro-Data}

One of the most important pre-requisites for forging any viable national insurance policies is the articulation of, and strict adherence to, the principles of statistical regularity and consistency in the day-to-day running of national insurance and underwriting programmes. An empirical analysis of some such principles constitutes the main concern of this section. 
First, we examine some of the official ratios used in the non-life insurance business and actuarial sciences in Nigeria. Our recourse to ratios - which are relative expressions - is a deliberate design to gain from their mathematical applicability for monitoring the relative stability in the growth of homogeneous and, in particular, heterogeneous variables (Langley 1970). Accordingly, we shall consider three standard ratios used in the non-life insurance business in Nigeria between 1989-1993, namely, "Loss Ratio". "Expense Ratio" and "Trade Ratio". These ratios are formally defined in what follows:

Loss Ratio is computed by dividing "incurred losses" by the "earned premium".

Expense Ratio is the division of "management expenses and commissions by the "premium IVritten".

Trade Ratio is the addition of loss ratio and expense ratio.

Functionally, the trade ratio is in inverse relationship with the financial and managerial fortunes of the given non-life insurance business concern. For instance, a trade ratio of over 100 per cent is an indication of a general business malaise - a leakage -which could lead to outright corporate failure, except the company concerned urgently ejects additional capital (say. from external savings) into the business to keep it afloat. On the other hand, a trade ratio which is consistently falling below 100 per cent is the most desirable one since it reflects a well-managed organization, enjoying financial and managerial stability (vide: Nigerian Insurance Digest 1994, page 31). From the foregoing analysis, it is clear, prima facie, that a trade ratio of exactly 100 per cent indicates an organization which is. as it were, tenuously perching on the "survival line" to break even.

Now, Table 4 presents a graphic picture of the relative performance of selected non-life insurance categories in Nigeria between 1989-93. The trade ratios displayed in column 14 of the table are curious and. therefore, deserve some further elucidations. Globally, the entire trade ratios, which range between 73.10 per cent and 104.54 per cent (in respect of Workmen's Compensation and Employer's Liability" and "Fire" categories, respectively) scarce!\} reflect any consistent regularity in the non-life insurance business in Nigeria during the period under review. This is evidently a direct reflection of the current economic downturn in the national economy, a situation which is detrimental to the successful operation of the general insurance and underwriting business ventures 
176 Annals of The Social Science Council of Nigeria, No. 7, January-December, 1995

Table 4

Mean Annual Loss, Expense and Trade Ratios of Selected Categories of Non-Life Insurance Companies in Nigeria 1989-93.

\begin{tabular}{|l|l|l|l|}
\hline Category' (1) & $\begin{array}{l}\text { Loss Ratio (\%) } \\
(2)\end{array}$ & $\begin{array}{l}\text { Expense Ratio (\%) } \\
(3)\end{array}$ & $\begin{array}{l}\text { Trade Ratio (\%) } \\
(4)\end{array}$ \\
\hline Motor & 68.91 & 42.41 & 103.24 \\
Fire & 45.71 & 48.99 & 104.54 \\
General Accident & 39.82 & 34.67 & 74.49 \\
$\begin{array}{l}\text { Marine. Aviation } \\
\text { and Transit } \\
\text { Workmen's } \\
\text { Compensation } \\
\text { Employer's } \\
\text { Liability } \\
\text { Miscellaneous }\end{array}$ & 38.54 & 42.18 & 100.72 \\
\hline Total & 46.85 & 36.25 & 73.10 \\
\hline
\end{tabular}

Source: Computed on the basis of data contained in Nigeria Insurance Digest 1994, p. 31-32

However, a closer examination of the individual trade ratios reveals the following three insurance and underwriting scenarios. Firstly, the "Marine, Aviation and Transit" category of non-life insurance business constitutes the median break-even sector (with a trade ratio of lt) 0.72 per cent). Second, the "Motor" and "Fire" categories are operating marginally below par (with the slightly "bloated" trade ratios of 103.24 per cent and 104.54 per cent, respectively). Finally, the trio categories of "General Accident", "Workmen's Compensation and Employer's Liability"and "Miscellaneous" holdings are fairing pretty satisfactorily (with the mildly "suppressed" trade ratios of 74.49 per cent, 73.10 per centand 97.17 per cent. respectively). The foregoing sectoral statistics are a further reflection of the relative instability and uncertainty in the non-life insurance sector in Nigeria today, a state of affairs which is also blamed on the contemporary economic crunch. However, the omnibus trade ratio of 92.74 per cent for the entire non-life holdings nation-wide is fairly encouraging and may well be the signs of some good things to come. 
Finally, we proceed to the application of statistical regularity in the life assurance industry, which is perhaps the most important of all forms of the general insurance and underwriting business ostensibly because of the obvious inevitability of death itself. However, since the exhaustive examination of the entire life assurance undertaking is clearly outside the scope of this paper, we intend to restrict ourselves to the examination of those rates and ratios for measuring the relative stability in the day-to-day running of the life assurance business.

For the purpose of the section, therefore, it is perhaps in order to examine some of the basic (relative) concepts of the so-called "Life Table" or, as George Willman (1993) more comprehensively terms it. "Mortality Tattle for Assured Lives". The concept of life table itself is. by the way. a glorified euphemism for "death rate" since the former is actually a programmed tabular display of the "order of dying" of a given contingent of the population (usually 1000) from birth to death.

The life table embodies such "vital" relative parameters as the survivorship ratios, mortality ratios and, perhaps the most important of all, the "mean expectation of life" - that is, the remaining length of life (usually expressed in years) which every one of us is expected to live over and above the specific age already attained by us right from birth to our final demise' In the developed countries, life expectancy is decidedly higher than in the developing countries for both sexes where, at the moment, they average 74 and 54 years, respectively (UN 1994). Therefore, since the "force of mortality"' is thus higher in the least developed countries of the world, the life expectancy indicators, which form an integral part of the life table, is perhaps more relevant in the articulation of the life assurance policies in these countries of the world today. Thus, David Bacon (1974) was writing mainly for the British audience - and, therefore, his general assertion should be accommodated with extreme caution - in his outright condemnation of the role of "life expectancy" in the life assurance calculus in stating that:

"Expectation of life" is never used to calculate premiums. The column (in the life table) is much less important in life assurance than is generally thought. As applied to an individual the term has little or no meaning, but is merely the average lifetime which will be enjoyed by a body of lives of a given age in similar circumstances. Its major function is to enable comparisons to be made between mortality tables".

All over the world, even life assurance company has its own life expectancy table which, in fact, is an adjusted or unadjusted version of the national one. In Nigeria, however, any information regarding the individual life expectancy tables of the life assurance underwriters are. unfortunately, kept as a "guarded secret". 
178 Annals of The Social Science Council of Nigeria, No. 7, January-December, 1995

However, the following life expectancy displayed in Table 5 is reproduced here from a local firm which pleaded anonymity.

Table

5 Life Expectation for Men

\begin{tabular}{|llllll|}
\hline Age & $\begin{array}{l}\text { Average } \\
\text { expectation } \\
\text { life (Years) }\end{array}$ & of Age & $\begin{array}{l}\text { Average } \\
\text { expectation of Age } \\
\text { life (Years) }\end{array}$ & $\begin{array}{l}\text { Average } \\
\text { expectation of } \\
\text { life (Years) }\end{array}$ \\
\hline 20 & 52 & 40 & 33 & 60 & 16 \\
21 & 51 & 41 & 32 & 61 & 15 \\
22 & 50 & 42 & 31 & 62 & 15 \\
23 & 49 & 43 & 30 & 63 & 14 \\
24 & 48 & 44 & 29 & 64 & 13 \\
25 & 47 & 45 & 28 & 65 & 13 \\
26 & 46 & 46 & 28 & 66 & 12 \\
27 & 45 & 47 & 27 & 67 & 11 \\
28 & 44 & 48 & 26 & 68 & 10 \\
29 & 44 & 49 & 25 & 69 & 10 \\
30 & 43 & 50 & 24 & 70 & 9 \\
31 & 42 & 51 & 23 & 71 & 9 \\
32 & 41 & 52 & 22 & 72 & 9 \\
33 & 40 & 53 & 21 & 73 & 8 \\
34 & 39 & 54 & 21 & 74 & 8 \\
35 & 38 & 55 & 20 & 75 & 7 \\
36 & 37 & 56 & 19 & 76 & 7 \\
37 & 36 & 57 & 18 & 77 & 6 \\
38 & 35 & 58 & 18 & 78 & 6 \\
39 & 34 & 59 & 17 & 79 & 5 \\
\hline
\end{tabular}

Now, for the sake of the computation of premiums, it is evident from Table 5 that the expectation of life is, for example, 47 more years for a man who is 25 years old now, and 24 more years for a man who is 50 today. If each takes out a policy to provide, say, $2,000,000$ on his death, we would naturally expect the man of 50 to pay each year about double the premium paid by the man of 25 . In other words, the underlying principle of the computation of most life-assurance premiums is that "the younger you are when you take out your policy, the lower the yearly premium you need to pay, and vice versa" (Willman 1993). Mathematically speaking, the premiums one pays as one progressively grows older is a monotonically increasing 
function and, ceteris paribus, the "arithmetic first differences" of such a function are likely to be the same, thus displaying some quantitative regularity throughout its entire domain.

As far as the contemporary life assurance position in Nigeria is concerned, "the 1991 Insurance Decree requires every insurer to maintain a fund sufficient enough to ensure payment of all policy obligations as and when they fall due. The amount of the fund should not be less than the mathematical reserves, an amount calculated on an actuarial basis taking into consideration the anticipated future premiums, assured rate of interest earnings and expected mortality experience of the aggregate company's policy" (Nigeria Insurance Digest. 1994).

The above decree has to a large extent brought some sanity into the hitherto troubled life assurance business in Nigeria. One can, therefore, observe some statistical regularity and relative stability in life assurance industry in Nigeria since the enactment of the decree as evident in Table 6, where columns 5 and 6 are of more .relevance to our investigations in this paper. Now, the claims ratios and expenses ratios displayed in these columns are "negative categories" such that the lesser they are the better for the companies concerned. However, since they reflect relative expressions of the overall performance of the life assurance business in Nigeria between 1989-93, we notice that there has been an overall monotonic decline in all the claims and expenses incurred b> the life assurance companies in Nigeria over these years.

Mathematically, again, the "arithmetic first differences" of the declining functions displayed are fairly stable, except in the case of the slightly bloated expenses ratio of 32.56 in 1993 which, however, does not affect the overall stable pattern of life assurance business in Nigeria over the years under consideration.

\section{Table 6}

\section{Comparative Statistics of Premiums, Claims and Management Expenses in Life Assurance Business in Nigeria between 1989-1993 (Expressed in Naira)}

\begin{tabular}{|l|l|l|l|l|l|}
\hline Year & Premiums & Net Claims & $\begin{array}{l}\text { Management } \\
\text { Expenses }\end{array}$ & $\begin{array}{l}\text { Claims } \\
\text { Ratio }\end{array}$ & $\begin{array}{l}\text { Expenses } \\
\text { Ratio }\end{array}$ \\
\hline$(1)$ & $(2)$ & $(3)$ & $(4)$ & $(5)$ & $(6)$ \\
\hline 1989 & $276,505,793$ & 65.480 .660 & 73.645 .515 & 23.7 & 26.6 \\
1990 & $281,553,440$ & 69.030 .880 & 96.838 .538 & 24.5 & 34.4 \\
1991 & $368,901,168$ & 97.236 .588 & 112.014 .093 & 26.4 & 30.4 \\
1992 & $666,811,408$ & 124.519 .199 & 135.652 .109 & 18.7 & 20.3 \\
1993 & $856,885,103$ & 155.219 .396 & 278.997 .026 & 18.11 & 32.56 \\
\hline
\end{tabular}

Source: Nigeria Insurance Digest 1994 A Statistical Journal of the Nigeria Insurance Association, p.48 
Our tentative conclusion, therefore, is that, partly because of the stringent guidelines of the insurance decree of 1991 and partly because of the 'uneasy calm' in the socioeconomic landscape at present, the life assurance business is slowly but steadily picking up in Nigeria. This development evidently constitutes a positive augury for Vision 2010.

\section{CONCLUSION}

Perhaps the best way to round off this paper is, first, to concede that our discussions in it are by no means exhaustive. However, we trust that, when applied with sufficient espritde corps, the basic tenets of the paper probably have the potentiality of meeting with most needs of both the macroeconomic planners and businessmen alike. Even here, there is still the over-riding desire to guard against the bald assumption merely applying the principles of statistical regularity and mass-scale phenomena - so richly extolled by the great Chebychev and his cohorts - will always provide an "all-weather" antidote, wily-nilly, against all the ills inherent in the lopsided economies of Africa today. It, therefore, behoves the various administrations to urgently provide the enabling environment for the principles to thrive in this continent. Such an enabling environment should infuse some noble virtues like patriotism, nationalism, dedication to duty, selflessness, sincerity, accountability and resourcefulness into the governments and the governed just like those that have recently brought about the "East Asian miracle" (Stiglitz 1996). Indeed, there is already some talk about the "Argentina-type" of development miracle.

Finally, we should also recognize that statistical methods themselves, are, fortunately or unfortunately, still in an amazing state of flux today, since they together constitute an ever-changing and dynamic process not only in the physical but also in the social world of ours. No wonder that, in accordance with the Maxwellian hypothesis, "in the physical sciences, as well as in the social sciences, statistical regularities never appear in pure form, but always have a material tinge to them" as eloquently demonstrated by their colossal theoretical and national policy significance.

\section{REFERENCES}

Asimov, Isaac (1966): Asimov on Chemistry London: MacDonald and James, p.83.

Billingsley, P. (1968): Convergence of Probability, Measures. New York: John Wiley.

Cox, D. R. et al (1965): The Theory of Stochastic Processes. London: Chapman and Hall. 
The Law of Statistical Regularity and Its Socio-Economic Significance

Eisberg, R. (1985): Quantum Physics. New York: John Wiley and Sons, pp. 375-414.

Gmurman, V. E. (1968): Fundamentals of Probability and Mathematical Statistics. London: Gliffe Books Limited, p.8.

Gnedenko, B. V. (1969): The Theory of Probablity. Moscow: Mir Publishing, p.29

Hakej Jaroslav, etal(1967): Probability in Science and Engineering. Prague: Academia Publishing House of Czechoslovak Academy of Science.

Gupta, S. P. (1985): Statistical Methods. New Delhi: Sultan Chand and Sons, p. E-4.4, E4.4 .

Hartley, H. O. (1980): "Statistics as a Science and as a-Profession". Journal of the American Statistical Association 75: 1-7.

Niven, W. D. (ed. 1927): "On Faraday's Lines of Force". The Scientific Papers of James Clerk Maxwell, Vol.1, Paris, edited by W. D. Niven, p. 159.

Revesz, Pal., (1968): The Lalvs of Large Numbers. New York and London: Academic Press, Inc.

Rose, S. M. (1972): Introduction to Probability Models. New York and London" Academic Press Inc.

Sachkov, Y. V. (1958): "An Appraisal of Statistical Regularities in Elementary Particle Physics". In Philosophical Problems of Elementary Particle Physics. Moscow: Progress Publishers, p.280.

Sheynin, O. B. (1970): "On the Early History of the Law of Large Numbers". In Pearson, E. S. et al: Studies in the History of Statistics and Probability, London: Griffin, p.231.

Yule, G. U. and Kendall, M. G. (1968): An Introduction to the Theory of Statistics. London: Charles Griffin, p.xvi.

Markov, A. A. (1931): The Calculus of Probabilities, 4th ed. Moscow: GIZ.

Maxwell, J. C. (1927): "On Faraday's Lines of Force". The Scientific Papers ofJ.C. Maxwell. Paris. 
182 Annals of The Social Science Council of Nigeria, No. 7, January-December, 1995

Mises, R. (1939): Probability, Statistics and Truth. New York.

Dynkin, E. B. (1963): Markov Processes and Related Problems. New York: OUP.

Chavalier, L. (1965): "Demographic History as an Instrument of History and of Demography" in D.V. Glass (ed.) Population in History. London: Gresham Press.

Marshall, Alfred (1892): Principles of Economics. London.

Leontief, H. L. (1929): Ein Versuch Zur Statisticschen Analyzse von Angebot and Nachfrage, Paris.

Schultz, H. (1928): Statistical Laws of Demand and Supply, with Special Application to Sugar, Chicago.

Lange, O. (1978): Introduction to Econometrics. New York: Pergamon Press.

Osayimweze, G. I. et al (1980): "International Inflation, Oil Crisis and the New

Economic Order". In Oil and the New International Economic Order. Ibadan: Nigerian Economic Society.

Langley, R. (1970): Practical Statistics. London: Pan Books Ltd.

Willman, G. (1973): The Penguin Guide to Insurance. London: Penguin Books. 